Note: This is a preprint of a manuscript being prepared for publication. Contents of this paper should not be quoted or referred to without permission of the author(s).

[To appear in Microstructure of Irradiated Materials, edited by I. M.Robertson, S. J. Zinkle, L. E. Rehn, and W. J. Phythian; Proceedings of Symposium Y, Fall 1994 Meeting of the Materials Research Society, Nov. 28-Dec. 2, 1994, Boston, MA.]

\title{
Amorphization threshold in Si-implanted strained SiGe alloy layers
}

T. W. Simpson, D. Love, E. Endisch, R. D. Goldberg, and I. V. Mitchell

Department of Physics

University of Western Ontario

London, Ontario N6A 3K7 Canada

T. E. Haynes

Solid State Division

Oak Ridge National Laboratory

Oak Ridge, Tennessee 37831 USA

J.-M. Baribeau

Institute for Microstructural Sciences

National Research Council

Ottawa, Ontario, K1A 0R6 Canada

\begin{abstract}
"The submitted manuscript has been authored by a contractor of the US Government under contract No. DEAC05-84OR21400. Accordingly, the US Government retains a nonexclusive, royaity-free license to publish or reproduce the published form of this contribution, or allow others to do so, for US Government purposes."
\end{abstract}

Oak Ridge National Laboratory

Oak Ridge, Tennessee 37831

managed by

MARTIN MARIETTA ENER GY SYSTEMS, INC.

for the

U.S. DEPARTMENT OF ENERGY

under contract DE-AC05-84OR21400.

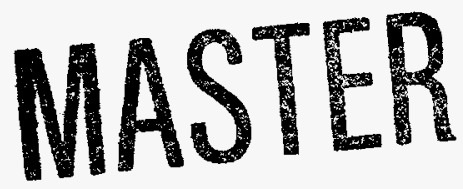

December 1994

DISTRIBUTION OF THIS DOCUMENT IS UNLIMITEO 


\section{DISCLAIMER}

This report was prepared as an account of work sponsored by an agency of the United States Government. Neither the United States Government nor any agency thereof, nor any of their employees, make any warranty, express or implied, or assumes any legal liability or responsibility for the accuracy, completeness, or usefulness of any information, apparatus, product, or process disclosed, or represents that its use would not infringe privately owned rights. Reference herein to any specific commercial product, process, or service by trade name, trademark, manufacturer, or otherwise does not necessarily constitute or imply its endorsement, recommendation, or favoring by the United States Government or any agency thereof. The views and opinions of authors expressed herein do not necessarily state or reflect those of the United States Government or any agency thereof. 


\section{DISCLAIMER}

Portions of this document may be illegible in electronic image products. Images are produced from the best available original document. 


\section{AMORPHIZATION THRESHOLD IN Si-IMPLANTED STRAINED SiGe ALLOY LAYERS}

T.W. Simpson", D. Love", D. Endisch", R.D. Goldberg " and I.V. Mitchell", T.E. Haynes"* and J.-M. Baribeau

*Department of Physics, University of Western Ontario, London, Ontario, N6A 3K7, Canada; **Solid State Division, Oak Ridge National Laboratory, Oak Ridge, TN, 37831, USA; ***Institute for Microstructural Sciences, National Research Council, Ottawa, Ontario, K1A 0R6, Canada

\section{ABSTRACT}

We have examined the damage produced by $\mathrm{Si}$-ion implantation into strained $\mathrm{Si}_{1-x} \mathrm{Ge}_{\mathrm{x}}$ epilayers. Damage accumulation in the implanted layers was monitored in situ by time-resolved reflectivity and measured by ion channelling techniques to determine the amorphization threshold in strained $\mathrm{Si}_{1-\mathrm{x}} \mathrm{Ge}_{\mathrm{x}}(\mathrm{x}=0.16$ and 0.29$)$ over the temperature range $30-110^{\circ} \mathrm{C}$. The results are compared with previously reported measurements on unstrained $\mathrm{Si}_{1-x} \mathrm{Ge}_{\mathbf{x}}$, and with the simple model used to describe those results. We report here data which lend support to this model and which indicate that pre-existing strain does not enhance damage accumulation in the alloy layer.

\section{INTRODUCTION}

Recent studies of ion induced damage in SiGe alloys have been motivated by the possible application to integrated circuit technology where implantation doping would be required. As a key step in the processing of semiconductor devices, it is important to understand the mechanisms for damage nucleation and growth which occur during ion implantation. It has been observed that the SiGe layers in $\mathrm{Si} / \mathrm{SiGe}$ superlattice structures are preferentially damaged during ion implantation to an extent far beyond that calculated from the increased damage cross-section of $\mathrm{Ge}$ over $\mathrm{Si}[1,2]$. It has since been shown that a small concentration of germanium has a significant stabilizing effect on damage retention during room temperature implantation with silicon ions [3]. Some understanding of this phenomenon can be sought through a simple model in which the mobility of point defects is the dominant factor controlling the growth of damage. This model was applied to a damage study in unstrained SiGe alloy layers [4]. In this study we report on new experimental data for strained layer $\mathrm{SiGe/Si}$ and compare them with the model.

\section{EXPERIMENT}

Two separate structures, a $37 \mathrm{~nm}$ layer of $\mathrm{Si}_{0.84} \mathrm{Ge}_{0.16}$ capped with $112 \mathrm{~nm}$ of $\mathrm{Si}$ and a $45 \mathrm{~nm}$ layer of $\mathrm{Si}_{0.71} \mathrm{Ge}_{0.29}$ capped with $115 \mathrm{~nm}$ of $\mathrm{Si}$ were used for this experiment. All the epitaxial layers were grown by molecular beam epitaxy (MBE) in a VG Semicon V80 system at the National Research Council [5]. Growth was performed on lightly doped $100 \mathrm{~mm}$ diam. Si (100) Czochralski wafers at a temperature of $450 \pm 25^{\circ} \mathrm{C}$ and at a growth rate of $0.2-0.4 \mathrm{~nm} / \mathrm{s}$. The substrate preparation consisted of a 50 minute treatment in a UV-ozone photo-reactor to remove surface hydrocarbons prior to loading in the growth chamber, followed by a $600 \mathrm{~s}$ heat treatment at $900^{\circ} \mathrm{C}$ under a small Si flux $(0.01 \mathrm{~nm} / \mathrm{s})$ to remove the surface oxide.

For subsequent measurements the wafers were cut into $1 \mathrm{~cm} \times 1 \mathrm{~cm}$ pieces. Strain and composition of the SiGe layers were determined by double axis $\mathrm{x}$-ray diffraction measurements ((400) rocking curves; \pm geometry) and by Rutherford backscattering spectrometry (RBS) [6] using channelling techniques. The Ge concentrations obtained from the $\mathrm{x}$-ray measurements were slightly higher than the values obtained by RBS [7], which could not be fully explained by lateral compositional variations of less than $1 \%$ over the wafer. 
Ion implantations were performed using the $1.7 \mathrm{MV}$ tandem accelerator at the University of Western Ontario. The strained $\mathrm{Si}_{1-\mathrm{x}} \mathrm{Ge}_{\mathrm{x}}$ alloy layers were bombarded with $\mathrm{Si}$ ions at energies of $80 \mathrm{keV}(x=0.16)$ and $200 \mathrm{keV}(x=0.29)$ with substrate temperatures of 30 to $110^{\circ} \mathrm{C}$. The energies were chosen to localize damage near the buried SiGe layer [8]. The ion current was maintained within the range of 40 to $50 \mathrm{nA} / \mathrm{cm}^{2}$ minimize effects due to ion flux [4]. The implant chamber allows time-resolved reflectivity (TRR) analysis [9] with a dual beam (633nm and $1.15 \mu \mathrm{m}$ wavelength) laser reflectivity system to monitor, in situ, changes in the optical properties of the implanted layer which accompany the build-up of damage. With this technique, the implanted dose at which damage saturates for a given ion flux and temperature can be determined with a single measurement. The reflectivity data may also indicate any differences in the mechanisms by which damage is accumulated. The damage levels in all samples were determined by Rutherford backscattering techniques and were quantified by measuring the yield of backscattered ions from germanium atoms in channelled and random directions.

\section{RESULTS AND DISCUSSION}

In their studies of ion-induced damage in unstrained SiGe alloys, Haynes and Holland $[4,10]$ applied a simple model based on the assumption that thermal diffusion of defects out from the cascade volume during the cascade lifetime reduces the retained damage[11]. In this model the fractional damage $F(T)$ versus fluence $\Phi$ is given by

$$
F(T)=\frac{\phi}{\phi_{0}}\left[1-\sqrt{\pi \phi_{0}} L_{0} e^{-Q 22 k_{0} T}\right]^{2}
$$

where $\Phi_{0}$ is the minimum fluence necessary to amorphize the alloy at low temperature, determined experimentally at $77 \mathrm{~K}$, and $L_{o}$ and $Q$ are parameters which describe the thermally activated mobility of defects. $L_{0}$ and $Q$ were fit to measured values of damage versus implant temperature for a fixed fluence and flux $\left(50 \mathrm{nA} / \mathrm{cm}^{2}\right)$. The results of those measurements are reproduced in table 1 . Inverting equation (1), with $F(T)=1$, yields an expression for the amorphization threshold

$$
\phi_{A}(T)=\frac{\phi_{0}}{\left[1-\sqrt{\pi \phi_{0}} L_{0} e^{-Q 2 k_{0} T}\right]^{2}}
$$

Table 1. Experimentally determined parameters from [4] and [11].

\begin{tabular}{llll}
$\mathrm{x}(\% \mathrm{Ge})$ & $\Phi_{\mathrm{o}}\left(\mathrm{cm}^{-2}\right)$ & $\mathrm{Q}(\mathrm{eV})$ & $\mathrm{L}_{\mathrm{o}}(\mathrm{nm})$ \\
\hline 0 & 1.5 & 0.13 & 4.0 \\
0.15 & 1.0 & 0.17 & 6.9 \\
0.35 & 0.9 & 0.40 & 140 \\
0.53 & 0.8 & 0.35 & 64 \\
1 & 0.5 & 0.26 & 27
\end{tabular}


The curves described by equation (2), when evaluated with the parameters given in table 1 for $x=0,0.15,0.35$ and 1 , are displayed in figure 1 . It can be seen that at low temperatures, where the influence of dynamic annealing is small, the amorphization dose is low and has a weak temperature dependence. The high temperature side of the curve shows that for each composition there is a region where the damage caused by the implanted ions is compensated by dynamic annealing, and the structure can not be amorphized. The amorphization dose is generally higher for lower Ge concentration, but the relation is not linear - the curve for $35 \%$ Ge is already very close to the $100 \%$ Ge curve.

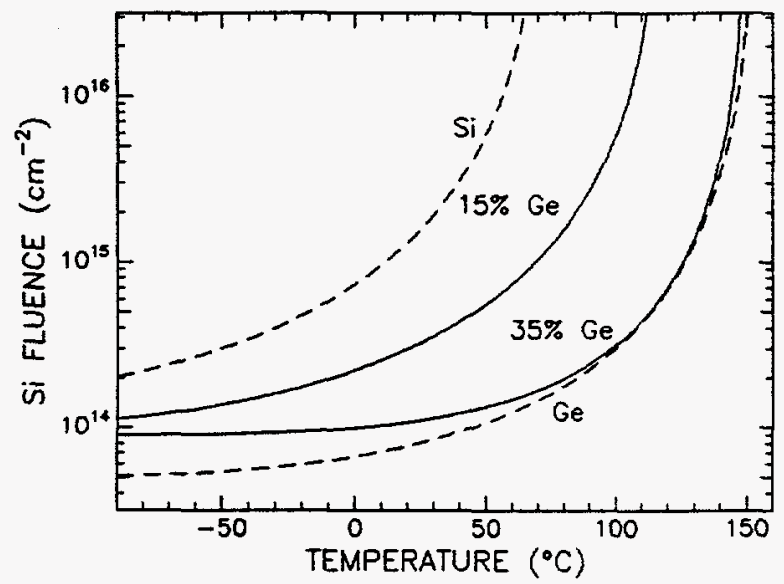

Figure 1 Predicted amorphization thresholds for $\mathrm{Si}, \mathrm{Si}_{0.85} \mathrm{Ge}_{0.15}, \mathrm{Si}_{0.65}, \mathrm{Ge}_{0.35}$ and $\mathrm{Ge}$ as a function of implant temperature, calculated from [4] and [11].

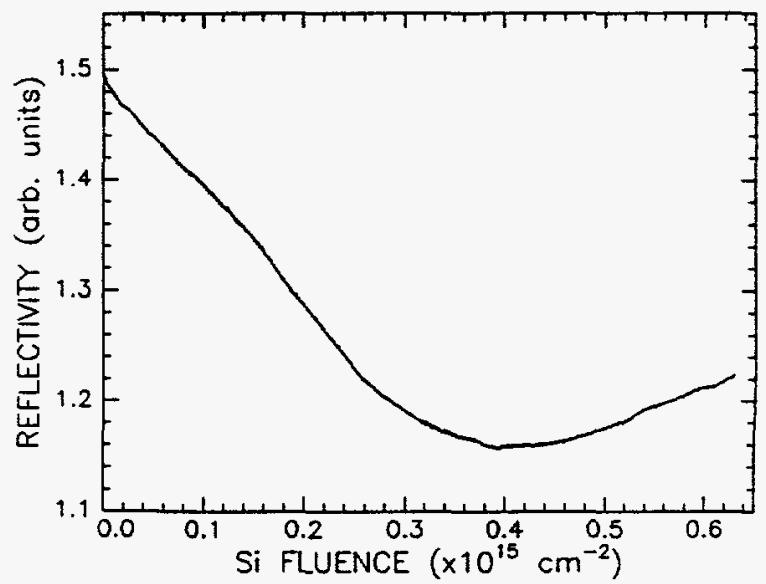

Figure 2 Reflectivity vs. Si-ion fluence for $\mathrm{Si}_{0.84} \mathrm{Ge}_{0.16}$ at $30^{\circ} \mathrm{C}$.

The reflectivity trace shown in figure 2 is typical of those recorded for low temperature implantation of a buried $\mathrm{Si}_{1-x} \mathrm{Ge}_{\mathrm{x}}$ layer for the $633 \mathrm{~nm}$ wavelength. Calibration by RBS techniques indicate that the early decline in reflectivity corresponds to the build-up of damage in the $\mathrm{Si}_{1-x} \mathrm{Ge}_{\mathrm{x}}$ layer and the increasing reflectivity which dominates the later part of the measurement results from the build-up of damage in the Si cap layer. Computer modelling of the reflectivity data using an effective medium approximation indicates that this trace is consistent with the uniform accumulation of damage about the $\mathrm{dE} / \mathrm{dx}_{\text {nuel }}$ peak, enhanced in the SiGe layer. The channelling spectra, shown in figure 3, confirm this picture.

From figure 3 and similar data for 30,50 and $70^{\circ} \mathrm{C}$, the fractional damage was quantified as a function of implanted ion fluence by measuring the backscattering yield of the germanium peak. The damage fraction $F$ can be calculated by $F=\left(Y_{i}-Y_{v}\right) /\left(Y_{r}-Y_{v}\right)$, where $Y_{i}$ and $Y_{v}$ are the channelling yields for the implanted and virgin sample and $\mathrm{Y}_{\mathrm{r}}$ is the random yield. The results for $x=0.16$ at $30^{\circ} \mathrm{C}$ are presented in figure 4. The data show that there is an initial slow buildup of damage followed by a more rapid approach to amorphization consistent with the mechanism reported for damage accumulation in bulk silicon $[12,13]$. In this study, we define the amorphization threshold by the fluence required for the Ge yield to reach $90 \%$ of the random level. The TRR data have been calibrated so the amorphization threshold can be measured from a single measurement. The threshold fluences for $90^{\circ} \mathrm{C}$ and $110^{\circ} \mathrm{C}$ in the $\mathrm{x}=0.16$ alloy were determined directly from TRR data.

To evaluate the model for the $x=0.29$ alloy, for which values of the required parameters were not available, measurements were performed on implants of $2 \times 10^{14}$ ions $/ \mathrm{cm}^{2}$ at substrate temperatures in the range $30-110^{\circ} \mathrm{C}$. The data are represented by the open circles in figure 5 . 
A least squares fit to equation 1 with the interpolated value of $\Phi_{0}=0.95 \times 10^{14} \mathrm{~cm}^{-2}$ was found for $\mathrm{Q}=0.26 \mathrm{eV}$ and $\mathrm{L}_{\mathrm{o}}=19.9 \mathrm{~nm}$ and is shown in figure 5 as a solid line. These parameters are consistent with earlier experimental results on relaxed layers (table 1). The predicted amorphization threshold for the strained $\mathrm{Si}_{0.71} \mathrm{Ge}_{0.29}$ is plotted in figure 6 . Below the critical temperature, the $x=0.29$ curve falls between those for $\mathrm{Si}_{0.85} \mathrm{Ge}_{0.15}$ and pure $\mathrm{Ge}$ indicating that the description applied to the unstrained material can also be applied to strained alloy layers.

The results of this work are compared to the predictions of the model in figure 6 . In the low temperature regime, $30-90^{\circ} \mathrm{C}$, the agreement is good, supporting the model and indicating that the accumulation of damage in the strained and unstrained alloy is not distinguishable. At higher temperatures, the data depart from the curve, suggesting that the temperature dependence of the threshold near the critical temperature is not as strong as is predicted.

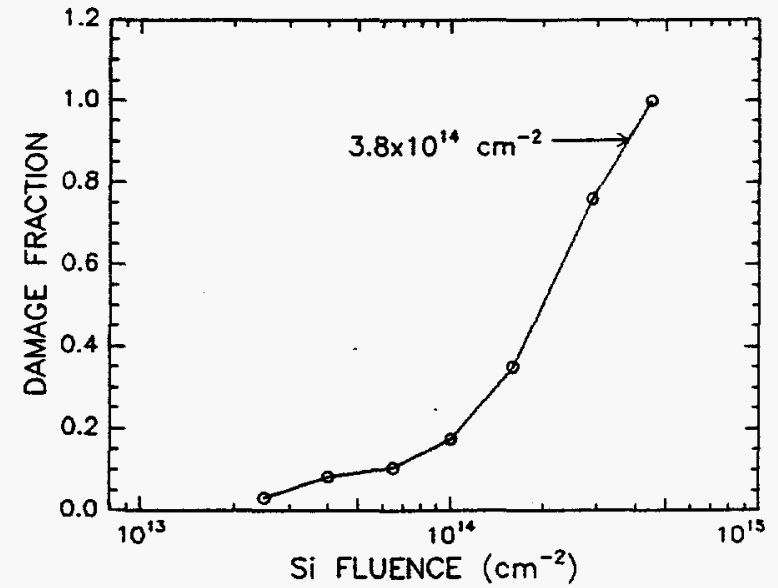

Figure 4 Damage vs Si-ion fluence for $\mathrm{Si}_{0.84} \mathrm{Ge}_{0.16}$ at $30^{\circ} \mathrm{C}$. These data confirm the interpretation of the TRR data shown in figure 2 , that the minimum reflectivity corresponds to amorphization of the SiGe layer.

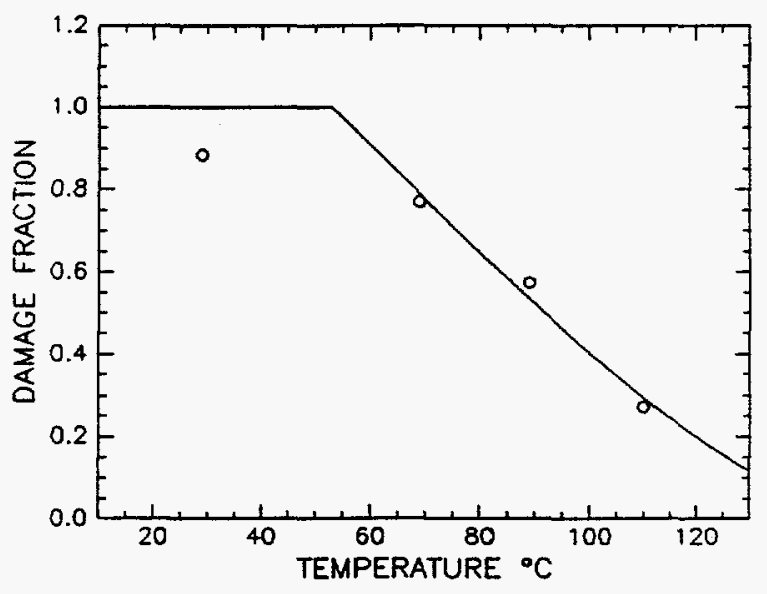

Figure 5 Damage vs. implant temperature for $\mathrm{Si}_{0.71} \mathrm{Ge}_{0.29}$ (open circles) for an implanted fluence of $2 \times 10^{14} \mathrm{Si}$-ions $/ \mathrm{cm}^{2}$. The solid line is the least squares fit of the data to equation (1). 


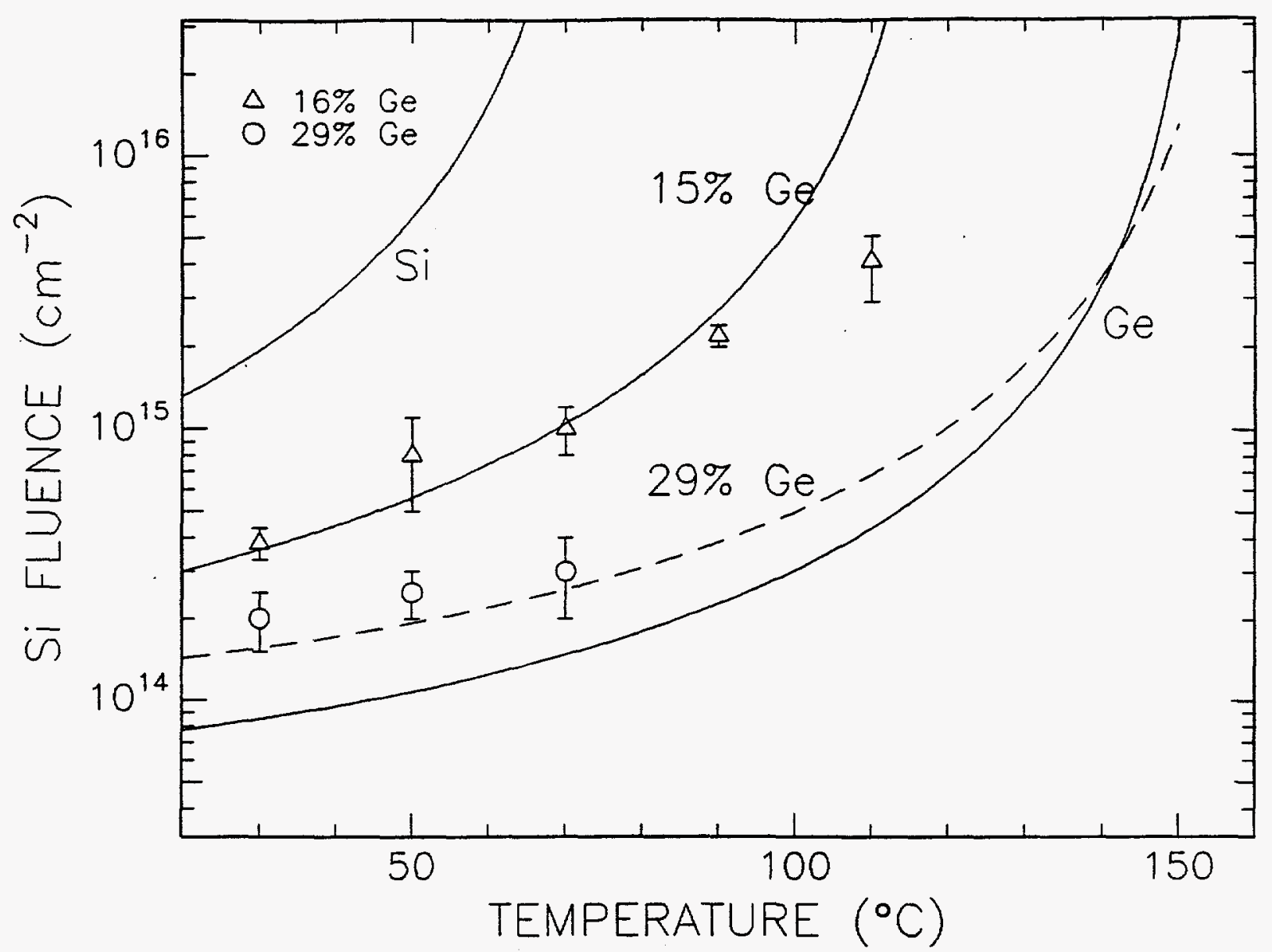

Figure 6 Measured amorphization threshold for $\mathrm{Si}_{0.71} \mathrm{Ge}_{0.29}$ (circles) and $\mathrm{Si}_{0.84} \mathrm{Ge}_{0.16}$ (triangles). Solid lines represent the predictions of equation (2) from $[4,10]$, dashed line from this work.

It is anticipated that another mechanism for damage accumulation, one not described by this simple model, and one which may be sensitive to pre-existing strain, dominates at higher temperatures. A significantly different TRR trace has been observed for the higher temperature implantations (not shown), substantiating this possibility. Indeed, the results are consistent with damage accumulation trends in several other materials which have been described in terms of nucleation limited amorphization [14,15]. A more detailed examination of the damage accumulation at higher temperatures is already in progress.

\section{CONCLUSIONS}

We have demonstrated that the model used by Haynes and Holland $[4,10]$ to describe the damage accumulation in a bulk (unstrained) SiGe alloy can be applied to predict the amorphization threshold for thin (strained) SiGe alloy layers in the temperature range of 30$90^{\circ} \mathrm{C}$. This result provides further evidence that, near room temperature, the selective amorphization of $\mathrm{SiGe}$ in $\mathrm{Si} / \mathrm{SiGe}$ multilayer structures is not due to the pre-existing strain, but rather to a reduction in dynamic annealing efficiency when germanium is present in silicon. Near the critical temperature, the results for the strained layers diverge from the predicted amorphization threshold, suggesting that a mechanism not described by the model dominates in that regime. 
The application of time resolved reflectivity (TRR) to measure the amorphization threshold of a buried SiGe layer, in situ, has been demonstrated in these studies. With this technique, a substantially improved measurement efficiency has been realized as compared with conventional post-implantation analysis.

\section{ACKNOWLEDGEMENTS}

Financial support for this work at UWO was provided by the Ontario Centres for Materials Research and at ORNL by the Division of Materials Sciences, U.S. Department of Energy, under contract DE-AC05-84OR21400 with Martin Marietta Energy Systems, Inc.

\section{REFERENCES}

1. D.J. Eaglesham, J.M. Poate, D.C. Jacobson, M. Cerullo, L.N. Pfeiffer and K. West, Appl. Phys. Lett. 58 (5) (1991) 523.

2. M. Vos, C. Wu, I.V. Mitchell, T.E. Jackman, J.-M. Baribeau and J. McCaffrey, Appl. Phys. Lett. 58 (9) (1991) 951.

3. D.Y.C. Lie, A. Vantomme, F. Eisen, T. Vreeland, Jr. and M.-A. Nicolet, J. Appl. Phys. 74 (10) (1993) 6039

4. T.E. Haynes and O.W. Holland, Appl. Phys. Lett. 61 (1) (1992) 61

5. J.-M. Baribeau, T.E. Jackman, D.C. Houghton, P. Maigné and M.W. Denhoff, J. Appl. Phys. 63 (1988) 5738

6. W.K. Chu, J.W. Mayer and M.-A. Nicolet, Backscattering Spectrometry (Academic Press, New York, 1978)

7. D. Endisch, D. Love, T.W. Simpson, I.V. Mitchell and J.-M. Baribeau, submitted to Nucl. Instr. Meth B.

8. J.F. Ziegler, J.P. Biersack and U. Littmark, The Stopping and Ranges of Ions in Solids (Permagon, New York, 1985)

9. G.L. Olson and J.A. Roth, Mater. Sci. Rep. 3 (1988) 1

10. T.E. Haynes and O.W. Holland, Nucl. Instr. Meth. B80 (1993) 901

11. F.F. Morehead and B.L. Crowder, Rad. Effects, 6 (1970) 27

12. G. Bai and M.-A. Nicolet, J. Appl. Phys. 70 (2) (1992) 649

13. J.S. Williams, K.T. Short, R.G. Elliman, M.C. Ridgway and R.D. Goldberg, Nucl. Instr. Meth. B48 (1990) 431

14. J.S. Williams, H.H. Tan, R.D. Goldberg, R.A. Brown and C.Jagadish, Materials Synthesis and Processing Using Ion Beams, R.J. Culbertson, O.W. Holland, K.S. Jones and K. Maex, eds. (Materials Research Society, Pittsburg, 1994) 15

15. R.D. Goldberg, J.S. Williams and R.G. Elliman, Materials Synthesis and Processing Using Ion Beams, R.J. Culbertson, O.W. Holland, K.S. Jones and K. Maex, eds. (Materials Research Society, Pittsburg, 1994) 259 